\title{
LOW INFLUENZA VACCINATION COVERAGE IN ASTHMATIC CHILDREN IN FRANCE IN $2006-7$
}

\author{
F Rance (rance.f@chu-toulouse.fr) ${ }^{1}$, C Chave ${ }^{2}$, J De Blic ${ }^{3}$, A Deschildre ${ }^{4}$, L Donato ${ }^{5}$, JC Dubus ${ }^{6}$, M Fayon ${ }^{7}$, A Labbe $^{8}$, \\ M Le Bourgeois ${ }^{3}$, C Llerena ${ }^{9}$, G Le Manach ${ }^{1}$, I Pin ${ }^{9}$, C Santos ${ }^{4}$, C Thumerelle ${ }^{4}$, M Aubert ${ }^{2}$, C Weil- Olivier ${ }^{10}$ \\ 1. Hôpital des Enfants, Toulouse, France \\ 2. Sanofi Pasteur MSD, Lyon, France \\ 3. Hôpital Necker Enfants-Malades, Paris, France \\ 4. Centre Hospitalier Régional Universitaire Lille, France \\ 5. Centre Hospitalier Universitaire Strasbourg, France \\ 6. Centre Hospitalier Universitaire Marseille, France \\ 7. Centre Hospitalier Universitaire Bordeaux, France \\ 8. Centre Hospitalier Universitaire Clermont Ferrand, France \\ 9. Centre Hospitalier Universitaire Grenoble, France \\ 10. Université Paris VII, Paris, France
}

In France, annual seasonal influenza vaccination has been recommended since 2000 for patients suffering from chronic respiratory diseases, including asthma. Since 1988, each year from September to December, a free influenza vaccination voucher is sent by the French Public Health Insurance authorities to patients with chronic respiratory disease, including severe asthma. In November 2006, this measure was extended to all asthmatic patients, irrespective of asthma severity. The present paper examines the 2006-7 influenza vaccination coverage rate (VCR) in 433 asthmatic children aged 6 to 17 years (mean age: 9.5 years; male: $61 \%$ ) who consulted a paediatric pulmonologist between March and September 2007 in eight hospitals throughout France. The influenza VCR was $15.7 \%$ for the $2006-7$ season (13.9\% for the $2005-6$ season and $10.9 \%$ for the $2004-5$ season). General practitioners vaccinated $72.1 \%$ of the children. "Lack of information" (42\%) was the most frequently reported reason for non-vaccination. Vouchers (received by $39.6 \%$ of the children) significantly increased the VCR ( $31 \%$ versus $5.9 \%$; $<<0.001)$. In France, in 2006-7, the influenza VCR in asthmatic children was far below the national public health objective (at least 75\% for the year 2008). Concerted action is needed to improve the influenza VCR in asthmatic children.

\section{Introduction}

Influenza can be a serious infection for patients with asthma because it may trigger or exacerbate asthma symptoms. About $80 \%$ of acute exacerbations in asthmatic children are triggered by a respiratory virus infection, and influenza virus is one of the most common viruses affecting the respiratory tract together with rhinovirus, respiratory syncytial virus and coronavirus, particularly during winter epidemics [1,2]. For the 2003-4 season, Bhat et al. reported that 12 of 132 (9\%) US children over six months of age with fatal influenza disease had asthma without other pulmonary disease [3].

Influenza vaccines are safe and effective in children [4,5], and recommended by the World Health Organization (WHO) for all children aged over six months with chronic conditions such as pulmonary and cardiovascular illness [6]. Most European countries have introduced annual influenza vaccination recommendations for high-risk patients from six months of age $[7,8]$.

In France, annual seasonal influenza vaccination has been recommended since 2000 for patients of any age from six months old suffering from diverse chronic diseases including respiratory disorders such as asthma [9]. One of the French national public health objectives for 2008 is to achieve a $75 \%$ influenza vaccination coverage rate (VCR) for all high-risk patients, including asthmatic patients [10]. In France, asthma prevalence reaches 10\% in children and 5\% in adults [11]; in 1998, 3.5 million people were suffering from asthma [12].

Since 1988 [13], each year from September to December a free influenza vaccination voucher is sent by the French Public Health Insurance authorities to patients with chronic respiratory disease, including severe asthma. In November 2006, this measure was extended to all asthmatic patients, irrespective of asthma severity [14].

There is only very limited specific data available on influenza vaccination coverage in French asthmatic children [15]. To the best of our knowledge, the present study is the first to specifically assess influenza VCR in French asthmatic children. The primary objective was to estimate the VCR for the 2006-7 season in French asthmatic children. The secondary objectives were to examine factors influencing vaccination uptake and reasons for nonvaccination for the 2006-7 season and to estimate the VCR for the previous two influenza seasons.

\section{Methods}

\section{Study design}

This descriptive observational study was performed in France from March to September 2007 (i.e. after the 2006-7 influenza season). The study was initially submitted to 11 investigators (paediatric pulmonologists) from nine French academic hospitals. 
A total of nine paediatric pulmonologists from eight academic hospitals agreed to participate in the study. The eight academic hospitals were located throughout France (Bordeaux, ClermontFerrand, Grenoble, Lille, Marseille, Paris, Strasbourg and Toulouse) and represented two thirds $(\mathrm{N}=8 / 12)$ of the French hospitals with a paediatric pulmonology unit.

Being an observational study which did not change the patient's usual medical management, the study protocol was not submitted to an ethics committee for approval, in line with current French legislation. Patients and their parents (or guardians) were provided by the paediatric pulmonologist with oral and written information, and oral consent was obtained from the parents before children were included in the study. Only patients whose parents gave their oral consent were included in the study. They were informed of their rights under the French information protection law. All questionnaire data were rendered anonymous using the Mapi-Naxis procedure validated by the Commission Nationale de l'Informatique et des Libertés (French Information Protection Commission) [16].

\section{Study population}

Each paediatric pulmonologist participating in the study consecutively included all children (girls and boys) who met the following inclusion criteria:

- aged $\geq 6$ and $\leq 17$ years in September 2006,

- seen at hospital by a paediatric pulmonologist,

- suffering from asthma diagnosed for at least six months,

- having a vaccination card enabling influenza vaccination status to be checked.

Diagnosis of asthma in children aged five and younger is considered to be difficult and unreliable according to the Global Initiative for Asthma (GINA) report, therefore only children $\geq 6$ years were included in the present study $[17,18]$.

\section{Data collection}

The paediatric pulmonologist filled in an anonymous questionnaire for each child included. The following demographic and clinical data were collected: birth date, sex, date of asthma diagnosis and asthma severity evaluated at inclusion according to the GINA classification [18] (i.e., intermittent, mild persistent, moderate persistent and severe persistent asthma). Parents were asked for the 2006-7 influenza season vaccination status of their children (yes or no) and receipt of a voucher for free influenza vaccination from the National Public Health Insurance authority for the 2006-7 season (yes or no). For vaccinated patients, the parents were asked for the identity of the vaccinator (i.e. health care professional who had administered the vaccine). The influenza vaccination date was recorded from the vaccination card. For children who had not been vaccinated parents were asked for the reasons for non-vaccination. Parents could give one or more than one reason for non-vaccination. The following reasons were specified in the questionnaire: lack of information, vaccine useless (disease considered as benign), forgotten or lack of time, vaccine considered as ineffective, vaccine considered as dangerous, allergy to egg, other allergy, vaccine contraindication, concomitant disease, current asthma exacerbation, afraid of injection. Parents could spontaneously report reasons for non-vaccination via the item "other reasons". Status and date of vaccination were recorded from the vaccination card for the 2004-5 and 2005-6 seasons.

\section{Statistical Methods}

All data were analysed by Mapi-Naxis (Lyon, France). Statistical analyses were performed on SPSS 14.0 software. A descriptive analysis for all the variables of the questionnaire was performed. For each variable, percentages were calculated using available data (missing data ignored). The influenza VCR value was given with its 95\% confidence interval $(95 \% \mathrm{Cl})$. The chi-square test was used for comparison of VCRs in asthmatic children with and without free vouchers; the significance threshold was set at 0.05 .

\section{Results}

\section{Study population characteristics}

Paediatric pulmonologists collected data for 435 asthmatic children. Data for two children were excluded from the analysis because they had been vaccinated against influenza before the official availability of the 2006-7 influenza season vaccine in France on 12 October 2006 [19]). Finally, data from 433 children were analysed.

In September 2006, at the beginning of the 2006-7 influenza season, the mean age of the analysed study population $(\mathrm{N}=433)$ was $9.5 \pm 2.9$ years (mean \pm standard deviation). The distribution according to age groups was as follows: $6-9$ years of age, $56.4 \%$ $(\mathrm{N}=244) ; 10-13$ years of age, $30.9 \%(\mathrm{~N}=134) ; 14-17$ years of age, $12.7 \%(\mathrm{~N}=55)$. The children were mainly boys $(61 \%)$. There were more boys than girls in the 6-9 year age group $(\mathrm{N}=145$ versus 90 , respectively) and in the $10-13$ year age group ( $N=88$ versus 42 , respectively) and fewer in the 14-17 year age group ( $N=22$ versus 31, respectively) (Table 1 ).

\section{T A B L E}

Study population characteristics

\begin{tabular}{|c|c|c|c|}
\hline $\begin{array}{l}\text { Demographic and clinical } \\
\text { characteristics }\end{array}$ & $\begin{array}{c}\text { All } \\
(\mathrm{N}=433)\end{array}$ & $\begin{array}{c}\text { Male } \\
(\mathrm{N}=255)\end{array}$ & $\begin{array}{c}\text { Female } \\
(\mathrm{N}=163)\end{array}$ \\
\hline Male: N (\%) & $255(61.0)$ & - & - \\
\hline Age (years): Mean \pm SD & $9.5 \pm 2.9$ & - & - \\
\hline Asthma duration (years): Mean \pm SD & $6.1 \pm 3.5$ & - & - \\
\hline Age at diagnosis (years): Mean \pm SD & $3.6 \pm 2.6$ & - & - \\
\hline \multicolumn{4}{|c|}{ Asthma severity, Global Initiative For Asthma (GINA) classification: N (\%)a, } \\
\hline 6-9 year old patients & $244(56.4)$ & 145 & 90 \\
\hline $\begin{array}{l}\text { Intermittent } \\
\text { Mild persistent }\end{array}$ & $\begin{array}{c}64(26.2) \\
110(45.1)\end{array}$ & $\begin{array}{l}38(26.2) \\
65(44.8)\end{array}$ & $\begin{array}{l}22(24.4) \\
40(44.4)\end{array}$ \\
\hline Moderate persistent & $60(24.6)$ & $38(26.2)$ & $22(24.4)$ \\
\hline Severe persistent & $10(4.1)$ & $4(2.8)$ & $6(6.7)$ \\
\hline 10-13 year old patients & $134(30.9)$ & 88 & 42 \\
\hline $\begin{array}{l}\text { Intermittent } \\
\text { Mild persistent }\end{array}$ & $\begin{array}{l}33(24.8) \\
43(32.3)\end{array}$ & $\begin{array}{l}26(29.9) \\
27(31.0)\end{array}$ & $\begin{array}{c}7(16.7) \\
13(31.0)\end{array}$ \\
\hline Moderate persistent & $41(30.8)$ & $23(26.4)$ & $17(40.5)$ \\
\hline Severe persistent & $16(12.0)$ & $11(12.6)$ & $5(11.9)$ \\
\hline 14-17 year old patients & $55(12.7)$ & 22 & 31 \\
\hline $\begin{array}{l}\text { Intermittent } \\
\text { Mild persistent }\end{array}$ & $\begin{array}{l}14(25.5) \\
17(30.9) \\
\end{array}$ & $\begin{array}{l}8(36.4) \\
8(36.4) \\
\end{array}$ & $\begin{array}{l}6(19.4) \\
9(29.0) \\
\end{array}$ \\
\hline Moderate persistent & $20(36.4)$ & $5(22.7)$ & $13(41.9)$ \\
\hline Severe persistent & $4(7.3)$ & $1(4.5)$ & $3(9.7)$ \\
\hline
\end{tabular}

Missing data:

aFor 15 patients data on sex missing

bFor 1 patient asthma severity data missing 
In September 2006, the mean duration of asthma in the analysed study population was $6.1 \pm 3.5$ years. Mean age at diagnosis was $3.6 \pm 2.6$ years. The severity of asthma according to the GINA classification [18] was known for all but one patient: $111(25.7 \%)$ had intermittent, 170 (39.4\%) mild persistent, 121 (28.0\%) moderate persistent and $30(6.9 \%)$ severe persistent asthma. In boys the highest proportion of intermittent asthma was found in 14-17 year-olds, mild persistent asthma in 6-9 year-olds and severe asthma in 10-13 year-olds. In girls the proportion of patients with severe persistent asthma increased with age and was highest in the age groups 10-13 and 14-17 years (Table 1).

\section{Influenza VCRs for the 2006-7, 2005-6 and 2004-5 seasons}

Of the 433 children analysed, 68 were vaccinated against influenza during the 2006-7 season. The global 2006-7 VCR was $15.7 \%$ ( $\mathrm{Cl} 95 \%$ : 12.6\%-19.3\%). The VCRs for the previous two seasons (2005-6 and 2004-5) were 13.9\% (Cl 95\%: $10.9 \%-17.3 \%$ ) (60 vaccinated children) and $10.9 \%(\mathrm{Cl} 95 \%$ : $8,2 \%-14.0 \%$ ) (47 vaccinated children), respectively.

\section{Influenza VCR for the 2006-7 season according to age, sex and severity of asthma}

A total of 29/244, 24/134, and 15/55 children from the 6-9, 10-13, and 14-17 age groups, respectively, were vaccinated during the $2006-7$ season. The influenza VCRs increased with age: $11.9 \%$ in the $6-9,17.9 \%$ in the $10-13$, and $27.3 \%$ in the $14-17$ age group (Table 2 ).

Girls aged 6-9 years were less frequently vaccinated than boys in the same age group (7.8\% versus $13.8 \%$ ), whereas girls aged $10-13$ years and $14-17$ years were more frequently vaccinated than

TA B L E 2

Vaccination coverage against influenza among asthmatic children according to age, sex, and asthma severity, France, influenza season 2006-7

\begin{tabular}{|l|c|c|c|c|}
\hline Groups & Number & Vaccinated & $\%$ & CI 95\% \\
\hline Total & 433 & 68 & 15.7 & $(12.6 ; 19.3)$ \\
\hline Age & & & & \\
\hline $6-9$ years & 244 & 29 & $11,9 \%$ & $(7,8 \%-16,0 \%)$ \\
\hline $10-13$ years & 134 & 24 & $17,9 \%$ & $(11,4 \%-24,5 \%)$ \\
\hline $14-17$ years & 55 & 15 & $27,3 \%$ & $(16,1 \%-41,0 \%)$ \\
\hline Sex: female & & & & \\
\hline $6-9$ years & 90 & 7 & $7,8 \%$ & $(3,1 \%-15,4 \%)$ \\
\hline $10-13$ years & 42 & 9 & $21,4 \%$ & $(10,3 \%-36,9 \%)$ \\
\hline $14-17$ years & 31 & 11 & $35,5 \%$ & $(19,2 \%-54,7 \%)$ \\
\hline Sex: male & & & & \\
\hline $6-9$ years & 145 & 20 & $13,8 \%$ & $(8,1 \%-19,5 \%)$ \\
\hline $10-13$ years & 88 & 14 & $15,9 \%$ & $(8,9 \%-25,3 \%)$ \\
\hline $14-17$ years & 22 & 4 & $18,2 \%$ & $(5,1 \%-40,3 \%)$ \\
\hline Asthma severity & & & & \\
\hline Intermittent & 111 & 7 & $6,3 \%$ & $(1,7 \%-10,9 \%)$ \\
\hline Mild persistent & 170 & 25 & $14,7 \%$ & $(9,3 \%-20,1 \%)$ \\
\hline Moderate persistent & 121 & 25 & $20,7 \%$ & $(13,4 \%-27,9 \%)$ \\
\hline Severe persistent & 30 & 10 & $33,3 \%$ & $(17,2 \%-52,9 \%)$ \\
\hline
\end{tabular}

boys in the same age groups $(21.4 \%$ and $35.5 \%$ versus $15.9 \%$ and $18.2 \%$, respectively) (Table 2 ).

A total of $7 / 111$ patients with intermittent asthma, 25/170 patients with mild persistent asthma, 25/121 patients with moderate persistent asthma and 10/30 patients with severe persistent asthma were vaccinated for the 2006-7 season. The influenza VCR increased with asthma severity, from $6.3 \%$ in children with intermittent asthma to $33.3 \%$ in those with severe persistent asthma (chi-square test: $\mathrm{p}<0.001$ ) (Figure 1 and Table 2).

\section{Influenza VCR for the 2006-7 season according to free vaccination voucher reception}

Data regarding the receipt of a free vaccination voucher for the 2006-7 season were available for 424 children (nine missing

\section{F I G U R E 1}

Vaccinated asthmatic children according to asthma severity (Global Initiative For Asthma - GINA classification), 2006-7 influenza season, France $(n=432)$

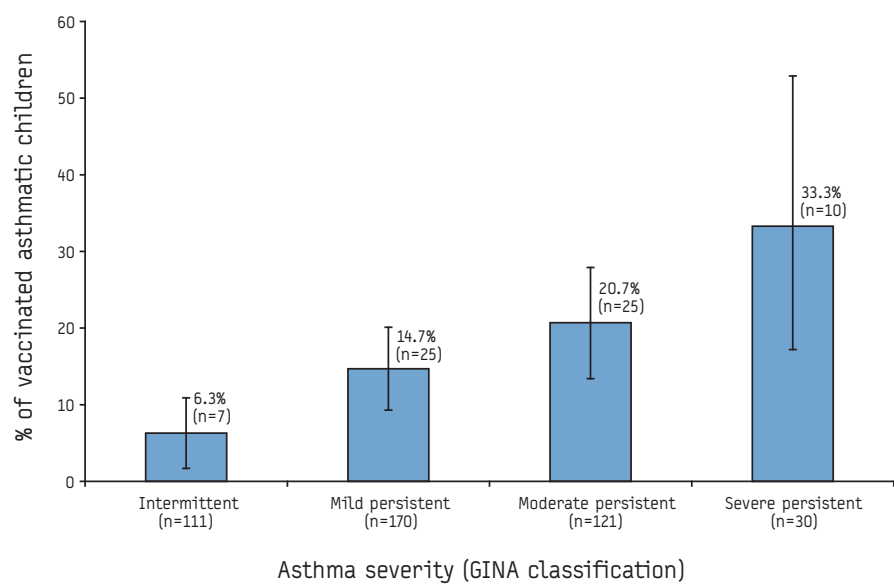

F I G U R E 2

Vaccinated and non-vaccinated asthmatic children according to reception of voucher ${ }^{\star}, 2006-7$ influenza season, France $(n=424)$

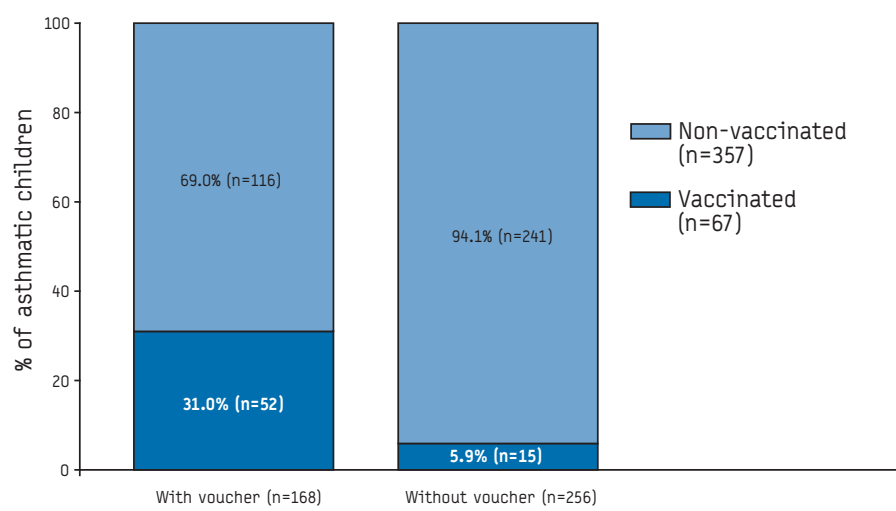

* A voucher for free influenza vaccination is provided by the French Public Health Insurance authorities to all asthmatic patients, irrespective of asthma severity 
values). According to the information provided by parents, 168 $(39.6 \%)$ children had received a voucher.

A total of $52(31.0 \%)$ of the 168 children who received a free voucher were vaccinated compared to 15 (5.9\%) of the 256 children who did not receive any voucher (Figure 2): Receiving a free vaccination voucher increased vaccination coverage in asthmatic children (31.0\% versus $5.9 \%$; chi-square test: $p<0.001$ ). A total of 116 of the 168 children who received a free voucher $(69.0 \%)$ were not vaccinated.

Vaccinators and reasons for non-vaccination in the 2006-7 season

The vaccination was mainly performed in private practice: 49 of the 68 children $(72.1 \%$ ) vaccinated for the 2006-7 influenza season were vaccinated by a general practitioner (GP), seven $(10.3 \%)$ by a family paediatrician, and three $(4.4 \%)$ by a hospital practitioner. Others were vaccinated by a nurse $(\mathrm{N}=5 ; 7.4 \%)$, their parents $(\mathrm{N}=3 ; 4.4 \%)$, or a pharmacist $(\mathrm{N}=1 ; 1.5 \%)$.

Reasons for non-vaccination were given for 357 of the 365 nonvaccinated children for the $2006-7$ season. Among the reasons specified in the questionnaire, "Lack of information" ( $N=150$; $42.0 \%)$, "Vaccine useless (disease considered as benign)" ( $N=70$; $19.6 \%)$, "Vaccine considered as ineffective or as dangerous" (globally $10.4 \%$ of cases: for each item $\mathrm{N}=21,5.9 \%$ and $\mathrm{N}=16$, $4.5 \%$ respectively), and "Forgotten or lack of time" ( $\mathrm{N}=31 ; 8.7 \%)$ were the most frequently reported reasons for non-vaccination (Figure 3). Allergy was a major motive for influenza non-vaccination for 17 children: 14 children (3.9\%) declared an "Allergy to egg". Among them, there was one case of egg allergy with clinical signs of anaphylactic shock and 13 with egg allergies but no history of anaphylactic shock. "Other allergy" was reported as reason for non-vaccination for three children $(0.8 \%)$. No allergy to one of the vaccine components was reported. A case of permanent rhinitis was considered as vaccine contraindication. The most frequent spontaneously reported reasons for non-vaccination were: "Vaccine not proposed" ( $\mathrm{N}=26,32.9 \%)$, "No medical indication" ( $\mathrm{N}=15$, $19.0 \%$ ), and "No favourable opinion of this vaccine by the family practitioner" ( $\mathrm{N}=10,12.7 \%)$.

\section{F I G U R E 3}

Reasons for non-vaccination of asthmatic children, 2006-7 influenza season, France ( $=357$, info missing for 8 children, multiple answers possible)

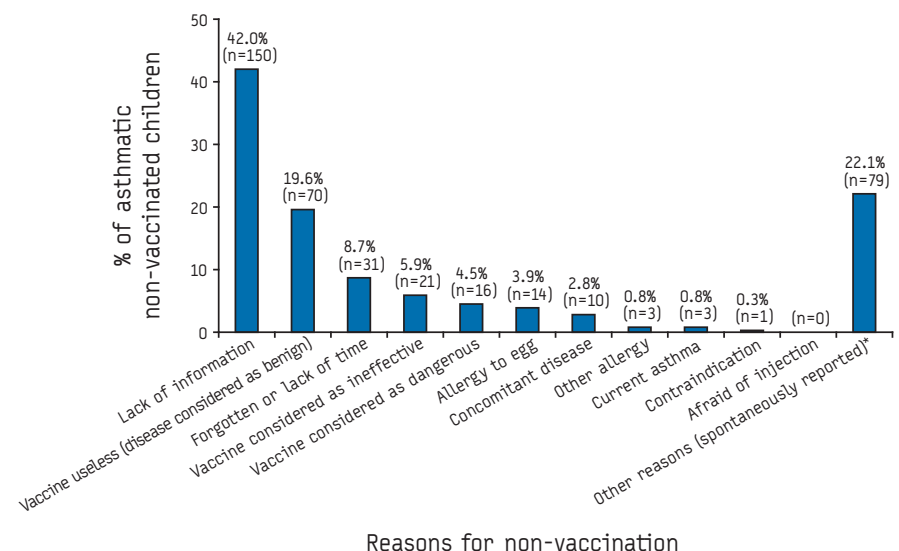

* The first three spontaneously reported reasons were: vaccine not proposed, no medical indication, no favourable opinion of this vaccine by the family practitioner

\section{Discussion}

Our study provides the first estimates of influenza VCR in France among asthmatic children.

It shows that the influenza VCR in asthmatic children was very low for the 2006-7 influenza season, as it had been over the previous two seasons. Only $15.7 \%$ of 433 asthmatic children $\geq 6$ years of age seen in a hospital by a paediatric pulmonologist were vaccinated against influenza for the 2006-7 season, the percentages were even lower for the 2005- 6 and 2004-5 seasons: $13.9 \%$ and $10.9 \%$, respectively. These results are consistent with previous studies that have shown low VCRs in children with chronic respiratory diseases. In a recent French study conducted in the Parisian Region (seven general paediatric wards) in 239 children with underlying chronic disease, Weil-Olivier et al. reported a $12.8 \%$ VCR for the 2003-4 influenza season in the subset of 39 children suffering from a chronic respiratory disorder, of whom 33 were asthmatic [15]. In Spain, Lopez de Andres et al. observed an influenza VCR of $19.9 \%$ in 2003 in 6,869 children suffering from a chronic respiratory disorder [20]. In the United States (US), a $29 \%$ influenza VCR in asthmatic children for the 2004-5 season and a $36.2 \%$ influenza VCR in asthmatic patients (children and adults) for the 2005-6 season were reported [21,22].

In our study, for the 2006-7 season, the influenza VCR did increase with the severity of asthma; one third of children with severe persistent asthma were vaccinated. In the US, for the 2004-5 season, children with current asthma who experienced an asthma attack or episode in the past 12 months had higher VCRs than those without an attack or episode (35.9\% versus $20.0 \%$, respectively); children with current asthma who had $\geq 10$ healthcare visits had higher VCRs than children without current asthma (42.0\% versus $14.6 \%$, respectively) [21].

Influenza VCR remained far below the French national public health objective of at least $75 \%$ for the year 2008 . Our study took place the year after the sending of a free influenza vaccination voucher to all asthmatic patients, irrespective of the severity of asthma, was implemented. Provision of a free voucher has already been shown to significantly improve VCR in children with cystic fibrosis in France [23]. According to the parents, only two in five asthmatic children have received a voucher for free vaccination and as the receipt of a voucher significantly improved VCR in asthmatic children, the reasons for non-receipt need to be analysed. Possible reasons are: asthma not declared to the Public Health Insurance authorities, lack of update of the database by the Public Health Insurance authorities, parents not remembering they had received the voucher, etc. After a period of adjustment, including provision of information about the voucher for free vaccination to the asthmatic children and their parents and updating of the database by the Public Health Insurance authorities, the decision to deliver a voucher to all asthmatic patients promises to help improve influenza VCR in asthmatic children in the near future. However, this measure, although necessary, will probably not be sufficient to reach the stated national objective, because receipt of a voucher during the 2006-7 season was not followed by influenza vaccination in as many as $69 \%$ of children.

The most frequently reported reasons given for non-vaccination were "Lack of information" (42.0\%), "Vaccine useless (disease considered as benign)" (19.6\%), "Vaccine considered as ineffective or dangerous" (in $10.4 \%$ of cases: $5.9 \%$ and $4.5 \%$ respectively), and "Forgotten or lack of time" (8.7\%). These findings emphasise 
the need for parents of asthmatic children to receive targeted information on the potential seriousness of influenza in asthmatic patients and on the tolerance and efficacy of influenza inactivated vaccine in children [4]. In conjunction with the voucher sent to all asthmatic patients, this information should also improve influenza VCR. Indeed, Schoeffer et al. [24] found that the clinical impact of influenza was underestimated or insufficiently well known to young people. These results were obtained from a study involving 2,131 German patients over 18 years of age, seen at a specialised medical centre for chronic respiratory disorders (asthma or chronic obstructive respiratory disease).

Anaphylactic hypersensitivity reaction to eggs or to one of the vaccine components is the only absolute contraindication to vaccination with trivalent inactivated influenza vaccine [25]. In the present study, 14 children $(3.9 \%)$ declared an "allergy to egg" as reason for non-vaccination against influenza. However, only one of these 14 children had ever presented clinical signs of anaphylactic shock subsequent to exposure to egg, a contraindication to inactivated influenza vaccine, suggesting that the other 13 may have been eligible for influenza vaccination. This illustrates that some children may have failed to be vaccinated because the specific contraindications for inactivated influenza vaccine are not well known.

The vaccinator was a GP in around two in three children and a family paediatrician for around one in ten. This result should be interpreted with caution taking into account the fact that included children were $\geq 6$ years old, an age which requires fewer visits to the paediatricians. Information on the potential seriousness of influenza in asthmatic patients and on the tolerance and efficacy of inactivated influenza vaccines in children should be provided by health care professionals during GP/paediatric consultations and/ or in the waiting room via posters, leaflets, etc. especially during the last trimester of the year.

One limitation of our study could refer to the nature of the asthmatic children enrolled. Investigators were strictly limited to paediatric pulmonologists to ensure the accurate recruitment of children with asthma. Since the study included only children seen in a hospital, it could have been possible that there were more severe persistent asthma cases in this population than in general practice; nevertheless $7 \%$ of asthma cases were severe persistent in the present study compared with $10 \%$ in asthmatic general population [12].

\section{Conclusions}

In France, the 2006-7 influenza VCR in asthmatic children was substantially lower than the national target of at least $75 \%$ by 2008 . The recent decision (November 2006) to deliver a free influenza vaccination voucher to all asthmatic patients, irrespective of asthma severity, has shown to improve the VCR in our study. To reach the national objective, however, this promising measure needs to be accompanied by timely information on the potential seriousness of influenza in asthmatic patients and by information about the tolerance and efficacy of inactivated influenza vaccines in children. Such information should be provided to, and by, health care professionals to parents of asthmatic children.

\section{Acknowledgements}

This work was part of the "Avancées Vaccinales", a French expert clinical and epidemiological research group.

The authors thank the staff of the paediatric chest units involved in the study, as well as Yann Bourhis and Rémi Gauchoux (Mapi-Naxis) for their help with data analysis, and Fabienne Péretz (independent medical writer) for her help in preparing this article.

\section{Funding statements}

Sanofi Pasteur MSD provided financial support for the logistics of the study.

\section{References}

1. Johnston SL. Overview of Virus-induced Airway Disease. Proc Am Thorac Soc. 2005;2:150-6.

2. Edwards MR, Kebadze T, Johnson MW, Johnston SL. New treatment regime for virus-induced exacerbations of asthma. Pulm Pharmacol Ther. 2006;19:320-34.

3. Bhat N, Wright JG, Broder KR, Murray EL, Greenberg ME, Glover MJ, et al. Influenza-associated deaths among children in the United States, 2003-2004. N Engl J Med. 2005;353:2559-67.

4. Neuzil KM, Dupont WD, Wright PF, Edwards KM. Efficacy of inactivated and coldadapted vaccines against influenza A infection, 1985 to 1990: the pediatric experience. Pediatr Infect Dis. J. 2001;20:733-40.

5. Ruben FL. Inactivated influenza virus vaccines in children. Clin Infect Dis. 2004;38(5):678-88.

6. Influenza vaccines. WHO position paper. Wkly Epidemiol Rec. 2005;33:279-88.

7. Van Essen GA, Palache AM, Forleo E, Fedson DS. Influenza vaccination in 2000 recommendations and vaccine use in 50 developed and rapidly developing countries. Vaccine. 2003;21:1780-5

8. Vaccination schedule for 2008 - Recommendations from the "Haut Conseil de la santé publique”. BEH. 2008;16-17:129-48. [In French].

9. Vaccination schedule for 2000 - Recommendations from the "Conseil supérieur d'hygiène publique de France”. BEH. 2000;27:115-7. [In French].

10. Loi relative à la politique de santé publique. Loi n²004-806 du 9 août 2004. [In French]. Available from: http://www.legifrance.gouv.fr

11. Institut national de Veille Sanitaire. Hospitalisations for asthma in metropolitan France, 1998-2002. Estimated using data from PMSI. [In French]. Available from: http://www.invs.sante.fr/recherche/index2. asp?txtQuery=asthma

12. Com-Ruelle L, Crestin B, Dumesnil S. Asthma in France by grade of severity. Question d'économie de la santé. 2000;25:1-4 [In French].

13. Communiqué “L'Assurance Maladie lance la campagne de vaccination antigrippale 2007”. [In French]. Available from http://www.ameli.fr

14. Arrêté du 23 octobre 2006 modifiant la liste des spécialités pharmaceutiques remboursables aux assures sociaux. Journal Officiel. 10 November 2006. [ In French].

15. Weil-Olivier C, Angoulvant F, Chevallier B, De Montalembert M, Gaudelus J, Quinet $B$, Labrune $P$, et al. Influenza vaccination coverage rate in children with underlying chronic disorders in 7 French pediatric wards. Arch Pediatr. 2006;13:1287-93. [In French].

16. French Information Protection Commission. [In French]. Available from: http:// www.cnil.fr Accessed October 20, 2008.

17. Global Initiative for Asthma (GINA). Pocket guide for asthma management and prevention in children. A pocket guide for physicians and nurses (Revised 2006). Available from: www.ginasthma.com/Guidelineitem. asp??l1=2\&l2=1\&intId= 49

18. Global Initiative for Asthma (GINA). Workshop report, global strategy for asthma management and prevention (Updated November 2006). http://www. ginasthma.com/Guidelineitem. asp?l1=2\&l2=1\&intId $=60$

19. Groupe régionaux d'observation de la grippe (GROG). 2006/2007 Influenza vaccine (Wednesday, October 4, 2006). [In French]. Available from: http:// www.grog.org/documents/vaccin_antigrippal_2006.pdf

20. Lopez-de-Andres A, Carrasco-Garrido P, Hernandez-Barrera V, Miguel AG, Jimenez-Garcia R. Coverages and factors associated with influenza vaccination among subjects with chronic respiratory diseases in Spain. Eur J Public Health. 2008;18:173-7. 
21. Centers for Disease Control and prevention (CDC). Influenza vaccination coverage among children with asthma - United States, 2004-05 influenza season. MMWR Morb Mortal Wkly Rep. 2007;56(9):193-6.

22. Centers for Disease Control and Prevention. Influenza vaccination coverage among persons with asthma--United States, 2005-06 Influenza season. MMWR Morb Mortal Wkly Rep. 2008;57(24):653-7.

23. Murris-Espin M, Aubert M, Bosdure E, Dubus J-C. Influenza vaccination coverage in patients with cystic fibrosis followed at 12 care centers in the Greater South Region of France for the season 2005/2006. Vaccine. 2008;26:5612-8.

24. Schoefer Y, Schaberg T, Raspe H, Schaefer T. Determinants of influenza and pneumococcal vaccination in patients with chronic lung diseases. J Infect. 2007;55:347-52.

25. Hanania NA, Atmar RL, Castro M. Influenza vaccine in patients with asthma. Expert Rev Vaccines. 2006;5(1):111-8.

This article was published on 23 October 2008.

Citation style for this article: Rance F, Chave C, De Blic J, Deschildre A, Donato L, Dubus J, Fayon M, Labbe A, Le Bourgeois M, Llerena C, Le Manach G, Pin I, Santos C, Thumerelle $C$, Aubert M, Weil-Olivier C. Low influenza vaccination coverage in asthmatic children in France in 2006-7. Euro Surveill. 2008;13(43):pii=19016. Available online: http://www. eurosurveillance.org/ViewArticle.aspx?ArticleId=19016 